\title{
LÍNGUA BRASILEIRA DE SINAIS: UMA REFLEXÃO ACERCA DA RELAÇÃO ENTRE ASSIMETRIA DE INFORMAÇÃO E BEM ESTAR
}

\author{
BRAZILIAN SIGN LANGUAGE: A REFLECTION ABOUT THE RELATIONSHIP \\ BETWEEN INFORMATION ASYMMETRY AND WELFARE
}

\section{LENGUA BRASILEÑA DE SEÑAS: UNA REFLEXIÓN SOBRE LA RELACIÓN ENTRE LA ASIMETRÍA DE INFORMACIÓN Y BIENESTAR}

\author{
Leydiane Ribeiro Duarte * \\ Priscila Casari ${ }^{* *}$
}

\section{Resumo}

Este artigo relata alguns dos resultados do trabalho realizado em um curso profissionalizante de Língua de Sinais. Apresenta uma breve discussão acerca do termo assimetria de informação, relacionando-o com o bem-estar, discorrendo também acerca da criação de leis sobre, além de apontar alguns dos benefícios relatados por alunos de Libras, com o aprendizado da Língua Brasileira de Sinais. As aulas fazem parte de um projeto da Secretaria do Trabalho e ocorreram na Faculdade Delta na cidade de Goiânia. A maioria das pesquisas apresenta as dificuldades que permeiam a comunicação do sujeito surdo; neste relato, porém, o objetivo é mostrar que a falta de conhecimento da língua, também acarreta desconforto para os ouvintes. A relevância do trabalho justifica-se pela necessidade da criação de políticas públicas que incentivem a divulgação e ampliação do uso da Língua de Sinais no país, como fator crucial na quebra de barreiras lingüísticas entre surdos e ouvintes.

Palavras-chave: Assimetria de informação, Língua de Sinais, Bem estar.

Em economia, conceitua-se assimetria de informação como uma falha de mercado que ocorre quando uma das partes não tem acesso à mesma informação que a outra parte. No caso específico dos surdos, considera-se que esses não têm acesso às informações orais, sejam essas em comunicações presenciais ou em áudio. Em 2002, com a Lei n ${ }^{0} 10.436$, a Língua Brasileira de Sinais foi reconhecida como uma das línguas oficiais do Brasil e, nos últimos anos, algumas iniciativas governamentais têm sido tomadas para a promoção da Língua, como programas de capacitação de profissionais no idioma e a abertura de cursos superiores de Letras - Libras para a formação de professores e intérpretes.

\footnotetext{
* Licenciada em Letras Libras pela Universidade Federal de Goiás, professora de Libras da Secretaria de Estado de Educação do Distrito Federal. E-mail: leydiane.ufg@gmail.com

** Doutora em Economia Aplicada pela Universidade de São Paulo, professora do Programa de Pós-Graduação em Economia (PPE) da Universidade Federal de Goiás. E-mail: pricasari@gmail.com
} 
As pesquisas na área da Educação geralmente consideram a perspectiva do sujeito surdo em relação à Língua de Sinais. Não encontramos, contudo, publicações que considerassem teorias econômicas que relacionassem o aprendizado de Libras por ouvintes ao acesso à informação e, consequentemente, ao bem estar dos sujeitos envolvidos. O objetivo deste trabalho é refletir sobre essa relação a partir de um relato de experiência. Espera-se contribuir, evidenciando uma relação aplicada da teoria econômica e também indicando possíveis resultados, sobre o bem estar, de políticas públicas que promovam o ensino / aprendizagem de Libras.

\section{Conceitos econômicos e a Língua Brasileira de Sinais}

Segundo a teoria econômica clássica, os indivíduos fazem opções de modo a maximizar o seu bem estar, ou seja, visando a utilidade de suas escolhas. Ocorre que, em Geral, os modelos econômicos, segundo Pindyck e Rubinfeld (2013) consideram que a informação é perfeita, ou seja, que no processo de escolha os indivíduos têm acesso a todas as informações disponíveis. De acordo com Varian (2012), quando as partes não têm acesso ao mesmo conjunto de informações, pode haver diferenças drásticas na natureza do equilíbrio de mercado, reduzindo o bem estar social.

Conforme Stiglitz (1999), os problemas causados pela informação assimétrica podem ser divididos em: seleção adversa e risco moral. A seleção adversa ocorre quando uma das partes não consegue selecionar adequadamente um produto ou serviço, enquanto o risco moral se dá quando uma das partes muda seu comportamento após efetuar a transação. Na interação entre surdos e ouvintes, caso ambos não consigam se comunicar na mesma língua, certamente haverá problemas de seleção adversa ou de risco moral, pois as pessoas surdas ficarão totalmente dependentes da presença de intérpretes ou da gesticulação, que muitas vezes é precária e empobrecida.

Dizeu e Caporali (2005, p. 584) afirmam que a Língua de Sinais é a "língua natural dos surdos, pois essa, a criança surda adquire de forma espontânea sem que seja preciso um treinamento específico". O governo federal entendeu essa necessidade e criou a lei 10.436, que dispõe sobre a Língua Brasileira de Sinais, reconhecendo a Libras como uma das línguas oficiais do país. A lei impõe Libras como disciplina curricular obrigatória nos cursos de 
formação de professores e exige que instituições e concessionárias de serviços públicos de saúde atendam adequadamente portadores de deficiência auditiva.

O setor público tenta, então, suprir essa necessidade, implantando cursos e capacitações para que profissionais das áreas da educação e da saúde tenham acesso a essa língua. A obrigação está na legislação, conforme indica o Decreto Federal 5.626 de 22 de dezembro de 2005, em seu Capítulo III, que salienta a necessidade de profissionais capacitados atenderem às pessoas com surdez ou perda auditiva.

Como já afirmamos, não encontramos publicações que analisem a relação entre o conhecimento de Libras e o bem estar do ponto de vista econômico, porém há depoimentos de pesquisadores da área da Saúde que mostram potenciais efeitos positivos do aprendizado de Libras sobre o bem estar dos envolvidos. Segundo Souza Júnior (2007), professor de Libras no curso de Fonoaudiologia da Faculdade de Medicina da Universidade Federal de Minas Gerais (UFMG):

[...] um curso de Libras é essencialmente um curso de línguas. Aprender uma nova língua é desenvolver uma nova maneira de se comunicar, consequentemente ampliando a capacidade expressiva de um indivíduo. Uma nova maneira de representar o pensamento, significar o mundo, é também outra forma de ver a realidade e se posicionar (SOUZA JÚNIOR, 2007, p.1).

Macedo (2013), professor titular do Instituto de Psicologia da Universidade de São Paulo, também ressalta a importância do bem estar derivado do aprendizado da Língua de Sinais por parte dos ouvintes:

Pensemos, por exemplo, nos benefícios da aprendizagem da Língua de Sinais para um ouvinte. Quando uma criança não surda aprende esta língua descobre ou multiplica seus poderes de comunicação gestual e simbólica. Aprende como é possível se comunicar com seus colegas surdos, constrói procedimentos alternativos aos processos de comunicação e interação humana. Descobre que língua é linguagem, forma de transmitir e processar informações. Ao compreender o valor comunicativo dos gestos e suas correspondências com aquilo que comunicam pode sentir-se surpreendida (MACEDO, 2013, p.1).

Dessa forma, acreditamos que é possível estabelecer uma relação entre a teoria econômica e o bem estar advindo do conhecimento de Libras. 


\section{Metodologia}

Para atingir o objetivo deste artigo, o método empregado foi o relato de experiência. Escolhemos esse método, pois propicia a reflexão qualitativa e em profundidade acerca de uma experiência, de modo que possamos evidenciar relações teórico-práticas.

O período de análise compreende os meses de março e abril de 2014, quando uma das autoras deste trabalho, professora Leydiane Duarte, atuou no ensino de dois cursos profissionalizantes, Libras I e II, para pessoas ouvintes. Os cursos fazem parte de um projeto da Secretaria do Trabalho e ocorreram na Faculdade Delta em Goiânia-GO. Nesse período, a professora conviveu com 18 alunos de diversas idades entre 18 e 65 anos. Dentre os alunos, 8 eram profissionais da Educação, 3 haviam se graduado em outras áreas, 2 estavam na graduação e 5 tinham ensino médio completo.

A partir dessa experiência foram possíveis reflexões sobre o tema e uma melhor compreensão de algumas das expectativas dos alunos e dos benefícios derivados do aprendizado de Libras por pessoas ouvintes. Após o período em que os cursos ocorreram, ao longo do ano de 2014, após discussões mais profundas sobre os resultados, procurou-se estabelecer relações entre a experiência pedagógica e situações próprias da economia, aplicando-se a teoria econômica, o que resultou no relato a seguir.

\section{Relato de experiência}

O início do curso de Libras I se deu com a indagação dos motivos que levaram cada aluno a estar ali e qual sua expectativa a respeito do curso. Naquele momento, tornou-se perceptível a relevância, para todos os participantes, do fator comunicação. Do total de dezoito alunos, dezesseis revelaram ter tido uma experiência ruim com surdos. Essas experiências passadas se deram devido a tentativas mal sucedidas de entender e ser entendido, em circunstâncias de comunicação. Muitos explicaram que a situação foi desagradável e que os encontros aconteceram em condições usuais, a caminho do trabalho, à espera de um ônibus, em lojas e em escolas. O dia ficou gravado em suas mentes, provocando angústia, como relataram. 
Outro fator, relatado pelos alunos, também provocou desconforto. Alguns já haviam se deparado com dois ou três surdos conversando em Libras, perto ou à distância de si. Os alunos relataram que se questionaram: O que eles estavam conversando? Estavam nervosos? Será que falavam sobre mim?

Percebemos, então, uma primeira relação possível com a teoria econômica, pois vemos que o fato de uma pessoa ouvinte não conseguir se comunicar com surdos traz uma perda de utilidade para o próprio ouvinte. Os alunos ouvintes relataram sentirem-se mal diante de situações em que as partes não tinham acesso à mesma informação, ou seja, quando houve informação assimétrica.

Como a proficiência em um idioma só pode ser obtida a partir do contato com falantes nativos da língua, sugerimos aos alunos que buscassem essa experiência. Na segunda semana de aula, três alunos informaram que já haviam procurado vizinhos, alunos e conhecidos surdos para exercitar o aprendizado e foi possível constatar que esse contato possibilitou um nível de aproveitamento do curso superior ao dos demais colegas. Ao término do nível I, os alunos expressaram sua satisfação com o curso, pois estavam se comunicando com os surdos que encontravam, ensinavam sinais aos membros de sua família e desejavam continuar o próximo nível do curso - Libras II, o que demonstra uma relação positiva entre o conhecimento da Língua Brasileira de Sinais e o bem estar dos alunos ouvintes.

Teve início, então, o nível II, que apresentou mais rigor técnico e profissional, além de discutir a cultura surda. Como os ouvintes percebem o mundo pela palavra ouvida e falada, entender que a pessoa surda carrega consigo experiências visuais e se expressa, principalmente, pelo uso de Libras faz muita diferença na comunicação.

Ao se encerrarem as aulas, foi questionado quantas pessoas desejavam atuar como intérpretes, ou ainda, ingressar em uma carreira profissional ligada à Libras. Apenas 4 pessoas responderam afirmativamente, as demais explicaram que foi prazeroso aprender a Língua de Sinais, mas que seu objetivo era somente conseguir se comunicar com os surdos e que estavam satisfeitos de, naquele momento, conseguir reduzir as barreiras linguísticas.

Nossa expectativa inicial era de que a maioria das pessoas visasse qualificação profissional, o que resultaria em maior empregabilidade e possibilidade de ganhos financeiros. No entanto, a maioria dos alunos demonstrou que os reais motivos de sua presença era 
eliminar falhas de comunicação e eventuais transtornos agregados a elas. Isso reforça, a nosso ver, a importância da redução da assimetria de informação para o aumento do bem estar dos alunos ouvintes.

Acreditamos que, ao apresentar possibilidades de expressão sem o uso da fala, o indivíduo ouvinte se vê surpreendido por ter diante de si elementos de uma outra cultura dentro de seu próprio país. Os benefícios não se limitam ao conhecimento de léxicos, mas elevam o nível de bem estar devido à eliminação de informações imperfeitas.

\section{Considerações finais}

O objetivo deste artigo foi relacionar o ensino / aprendizado de Libras ao acesso à informação, a novos conhecimentos e, consequentemente, ao bem estar, evidenciando uma aplicação de conceitos da teoria econômica. A partir da experiência relatada, observou-se que a maioria dos alunos ouvintes do curso de Libras, onde foi realizada a pesquisa para este trabalho, havia sentido, em algum momento, "perda de utilidade" ao não conseguir se comunicar com surdos, mas após o curso, sentia maior satisfação por poder reduzir os problemas de comunicação com conhecidos surdos.

Para este grupo de alunos ouvintes houve uma relação de causalidade entre o conhecimento da Língua Brasileira de Sinais, a redução de assimetria de informação e o aumento do nível de bem estar. Deve-se considerar, no entanto, que a conclusão de nossa reflexão não é generalizável. O objetivo foi utilizar uma experiência pedagógica como um exemplo da aplicação da teoria econômica, mostrando efeitos positivos em termos de bem estar, sugerindo a oportunidade de novas políticas de capacitação de pessoas ouvintes em Libras, pois o aprendizado da Língua Brasileira de Sinais (Libras) por ouvintes poderia, certamente, reduzir a assimetria de informação entre surdos e ouvintes.

A partir desse resultado, seriam pertinentes futuras pesquisas que analisem uma amostra maior de pessoas, ou que comparem os efeitos sobre o bem estar do aprendizado de Libras por surdos e ouvintes em escolas e ambientes inclusivos, ou ainda, que explorem outras relações entre a teoria econômica e o bem estar no dia a dia da população. 


\begin{abstract}
This article is about an experience report of conclusions drawn by a teacher working in a professional Sign Language course. We present a brief discussion on the term asymmetry of information relating it to the welfare concept. We also talk about creating laws that promote the Brazilian Sign Language (Libras) and point out the benefits that Libras students had while learning the new language. The classes were part of a project of the Department of Labor and took place at Delta College in the city of Goiania. Most of the researches done show the difficulties that permeate the communication of the deaf subject; in this report, however, the goal is to show that the lack of knowledge of the language is also detrimental to the listeners. The relevance of the work is justified by the need to create public policies that encourage the dissemination and expansion of the use of Sign Language in the country as a crucial factor in breaking down language barriers.
\end{abstract}

Keywords: Information asymmetry, Sign Language, Welfare.

\title{
Resumen
}

Este artículo relata algunos resultados del trabajo desarrollado en un curso profesionalizante de Lengua de Señas. Presenta una breve discusión acerca de la expresión asimetría de información relacionándolo al bienestar, discutiendo, al mismo tiempo, la creación de leyes que promocionen la LIBRAS. Además de eso, señala algunos de los beneficios que los estudiantes de LIBRAS relatan haber obtenido al aprender esa lengua. Las clases son parte de un proyecto de la Secretaría del Trabajo y se desarrollaron en el Instituto de Educación Superior Delta, en la ciudad de Goiânia. Grande parte de las investigaciones presenta las dificultades por las que atraviesa la comunicación del sujeto sordo; en este relato, sin embargo, el objetivo es mostrar que la falta de conocimiento de la lengua también trae incómodos para los oyentes. La relevancia del trabajo se justifica por la necesidad de crear políticas públicas que fomenten la difusión y expansión del uso de la lengua de señas en el país, al ser observada como un factor crucial para la ruptura de barreras lingüística entre sordos y oyentes.

Palabras-clave: Asimetría de información, Lengua de Señas, Bienestar.

\section{Referências}

BRASIL. Decreto no 5.626 de 22 de dezembro de 2005. Regulamenta a Lei 10.436 que dispõe sobre a Língua Brasileira de Sinais e o Art. 18 da Lei n ${ }^{\circ} 10.098$ de 19 de dezembro de 2000. Disponível em: http://www.planalto.gov.br/ccivil_03/_ato20042006/2005/decreto/d5626.htm Acesso em 28 de maio de 2014.

BRASIL. Lei $\mathbf{n}^{\circ} \mathbf{1 0 . 4 3 6}$ de 24 de abril de 2002. Dispõe sobre a Língua Brasileira de Sinais Libras e dá outras providências. Disponível em: http://www.planalto.gov.br/ccivil_03/leis/2002/110436.htm Acesso em: 09 de maio de 2014. 
DIZEU, Liliane Correa Toscano de Brito; CAPORALI, Sueli Aparecida. "A língua de sinais constituindo o surdo como sujeito". Educação e Sociedade, Campinas, v. 26, n. 91, p. 583 597, Maio/Agosto, 2005.

MACEDO, Lino. Benefícios da aprendizagem da Língua de Sinais para todos. 2013. Disponível em:

http://diversa.org.br/artigos/artigos.php?id=600\&/beneficios_da_aprendizagem_da_lingua_de _sinais_para_todos Acesso em: 2 de abril de 2014

PINDYCK, Robert S.; RUBINFELD, Daniel L. Microeconomia. $8^{\text {a }}$ ed. São Paulo: Pearson Education, 2013.

SOUZA JÚNIOR, Marcos Antônio. Libras promove a inclusão. 2007. Disponível em: http://www.medicina.ufmg.br/noticias/?p=331 Acesso em: 2 de abril de 2014.

STIGLITZ, Joseph E. Economics of the Public Sector. $3^{\text {a }}$ ed. New York: Norton, 1999.

VARIAN, Hal R. Microeconomia: uma abordagem moderna. $8^{a}$ ed. Rio de Janeiro: Campus, 2012. 